NBER WORKING PAPER SERIES

\title{
MEASURING THE VALUE OF A STATISTICAL LIFE: PROBLEMS AND PROSPECTS
}

\author{
Orley Ashenfelter \\ Working Paper 11916 \\ http://www.nber.org/papers/w11916 \\ NATIONAL BUREAU OF ECONOMIC RESEARCH \\ 1050 Massachusetts Avenue \\ Cambridge, MA 02138 \\ January 2006
}

Prepared as the J. Denis Sargan Lecture presented at the Royal Economic Society Meetings in Nottingham, March 2005.Orley Ashenfelter is the Joseph Douglas Green 1895 Professor of Economics, Princeton University. He is indebted to Michael Greenstone for many helpful discussions. The views expressed herein are those of the author(s) and do not necessarily reflect the views of the National Bureau of Economic Research.

(C2006 by Orley Ashenfelter. All rights reserved. Short sections of text, not to exceed two paragraphs, may be quoted without explicit permission provided that full credit, including $(\mathcal{C}$ notice, is given to the source. 
Measuring the Value of a Statistical Life: Problems and Prospects

Orley Ashenfelter

NBER Working Paper No. 11916

January 2006

JEL No. J17, H43, I18, R4

\begin{abstract}
$\underline{\text { ABSTRACT }}$
Tradeoffs between monetary wealth and fatal safety risks are summarized in the value of a statistical life (VSL), a measure that is widely used for the evaluation of public policies in medicine, the environment, and transportation safety. This paper demonstrates the widespread use of this concept and summarizes the major issues, both theoretical and empirical, that must be confronted in order to provide a credible estimate of a VSL. The paper concludes with an application of these issues to a particular study of speed limits and highway safety.

Orley Ashenfelter

Industrial Relations Section

Firestone Library

Princeton University

Princeton, NJ 08544

and NBER

c6789@princeton.edu
\end{abstract}


Robber: "This is a stick-up. Your money or your life."

(pause)

Robber: "Look, bud. I said your money or your life." Jack Benny: "I'm thinking it over."

The Jack Benny Radio Program, March 8, 1948

Public choices about safety in a democratic society require estimates of the willingness of people to trade off wealth for a reduction in the probability of death. Estimates of these trade-offs are used in evaluating environmental issues, public safety in travel, medical interventions and in many other areas. It has become common to call this trade-off the value of a statistical life (VSL). The purpose of this paper is to provide a summary discussion of the major problems encountered in measuring the value of a statistical life. These problems are both theoretical issues of interpretation, and difficult problems of measurement. ${ }^{1}$

A key issue to clarify at the outset is the precise meaning of the phrase "the value of a statistical life," which many no doubt find distasteful. Indeed, how can the value of your own life even be calculated? The answer, of course, is that unlike the notorious skinflint comedian Jack Benny, we would give up all our wealth to avoid the certain loss of our own life, so there is no upper bound on this definition of the value of life. Yet, at the same time, everyone takes risks, some of which could be avoided by the expense of either time or money. When we expend

\footnotetext{
${ }^{1}$ Thaler and Rosen (1976) provide the first careful discussion of this topic. They are responsible for much of the terminology used and for some of the earliest measurement.
} 
wealth to avoid potentially fatal risks, or accept wealth to take such risks, we are implicitly defining a trade-off between wealth and the probability of death, whether we like it or not. The ratio of the wealth we are willing to accept in exchange for a small change in the probability of a fatality is expressed in units of "dollars per death," or the dollar value of a fatality. It is for this reason that this trade-off is often called the value of a "statistical" life. The word "statistical" is intended to make it clear that this is, despite its colloquial familiarity, a technical term.

\section{What is the VSL?}

To make matters concrete, suppose that an economic agent is willing to accept the consequences of an action that involves an increase of at least $\Delta \mathrm{W}$ in wealth in return for an increase in the probability of a fatality of $\Delta \mathrm{P}$. Then $\mathrm{V}^{*}=$ $\Delta \mathrm{W} / \Delta \mathrm{P}$ is an acceptable trade-off to that agent, and it is the VSL for the tradeoff described by this particular fatality risk. $V^{*}$ need not be a constant, of course, and would certainly be expected to depend on the level of $\mathrm{P}$ at which it is evaluated, a person's wealth, and perhaps many other factors, including personal preferences.

How is $\mathrm{V}^{*}$ to be measured? It is apparent that $\mathrm{V}^{*}$ is not directly observable, so an indirect method is required for measurement. One possibility is simply to ask the agent. Though this procedure has its advocates, and certainly has been 
used in practice, for many it suffers from its purely hypothetical nature. That is, would the same answer be revealed if a "real" decision corresponding to the hypothetical question were taken? The primary advantage of simply asking is, of course, the ease with which it can be done, especially in situations where it is difficult to observe real choices, and this is no doubt a key reason for its popularity.

An alternative approach is based on an agent's revealed preference.

Suppose we consider an offer $\mathrm{V}$ to accept an action with known wealth and fatality risk. In this case $\mathrm{V}$ is known because it is possible to calculate the numerator and denominator that comprise it. If the agent accepts the risk, then we know that $\mathrm{V}>\mathrm{V}^{*}$. That is, the wealth received was worth more than the fatality risk incurred. Thus, the observable $\mathrm{V}$ provides an upper bound on $\mathrm{V}^{*}$, but it is not possible to say more without further assumptions.

To do this, assume that $\mathrm{V}^{*}$ is determined by some variables $\mathrm{X}$, which are observable, and some that are unobservable, $\varepsilon$, so that for the ith unit (1) $\mathrm{V}_{\mathrm{i}}^{*}=\alpha^{\prime}+\beta^{\prime} \mathrm{X}_{\mathrm{i}}+\varepsilon_{\mathrm{i}}^{\prime}$.

Likewise, assume that $\mathrm{V}$ is determined by other factors $\mathrm{Z}$, so that (2) $\mathrm{V}_{\mathrm{i}}=\alpha+\beta \mathrm{Z}_{\mathrm{i}}+\varepsilon_{\mathrm{i}}$.

Since the risk will be accepted if $\mathrm{V}_{\mathrm{i}}>\mathrm{V}_{\mathrm{i}}{ }^{*}$, the probability that the higher risk is accepted is thus:

$$
\operatorname{Pr}(\text { Acceptance }) \quad=\operatorname{Pr}\left(\mathrm{V}_{\mathrm{i}}>\mathrm{V}_{\mathrm{i}}{ }^{*}\right)
$$




$$
=\operatorname{Pr}\left(\varepsilon_{\mathrm{i}}-\varepsilon_{\mathrm{i}}{ }^{\prime}<\alpha-\alpha^{\prime}+\beta Z_{\mathrm{i}}-\beta^{\prime} \mathrm{X}_{\mathrm{i}}\right) .
$$

It is apparent that the average value of $\mathrm{V}$ among those who accept the risk, $\mathrm{E}(\mathrm{V} \mid$ Accept $)=\mathrm{E}\left(\mathrm{V} \mid \mathrm{V}>\mathrm{V}^{*}\right)$, must be at least as great as $\mathrm{E}\left(\mathrm{V}^{*}\right)$, the unconditional average value of a statistical life among both those who accept and those who do not accept the risk. Since the left hand side of equation (2) is only observed for those who accept the risk, estimation of the parameters of equation (2) may suffer from selection bias.

To make further progress further assumptions are required. Assume, for example, that $\varepsilon_{\mathrm{i}}$ and $\varepsilon_{\mathrm{i}}$ ' are joint normally distributed, so that (3) can be estimated by the probit function:

$$
\operatorname{Pr}(\text { Adoption }) \quad=F\left[\left(\alpha-\alpha^{\prime}+\beta Z_{i}-\beta^{\prime} X_{i}\right) / \sigma\right]
$$

where $\sigma=\sigma_{\varepsilon}-\varepsilon^{\prime}$ is $\left(\operatorname{var}\left(\varepsilon-\varepsilon^{\prime}\right)\right)^{1 / 2}$ and $\mathrm{F}[\bullet]$ is the cumulative unit normal distribution. It is apparent that even with this functional form assumption, it is only possible to obtain estimates of $\left(\alpha-\alpha^{\prime}\right) / \sigma, \beta / \sigma, \beta^{\prime} / \sigma$. The separate parameters in equations (1) and (2) cannot be identified from this probit function alone.

However, since $V_{i}$ is observable, it is possible to estimate (2) by the usual selection corrected regression methods (Heckman 1979). In particular,

$$
\mathrm{E}\left(\mathrm{V}_{\mathrm{i}} \mid \text { acceptance }\right)=\alpha+\beta Z_{\mathrm{i}}+\rho \sigma_{\varepsilon} \lambda_{\mathrm{i}},
$$

where $\rho$ is the correlation between $\varepsilon$ and $\varepsilon^{\prime}, \lambda_{\mathrm{i}}=\lambda\left(\mathrm{X}_{\mathrm{i}}, \mathrm{Z}_{\mathrm{i}}\right)=\mathrm{f}\left(\mu^{\prime} \mathrm{W}_{\mathrm{i}}\right) / \mathrm{F}\left(\mu^{\prime} \mathrm{W}_{\mathrm{i}}\right)$, and $\mu^{\prime}$ consists of the vector $\left[\alpha-\alpha^{\prime}, \beta,-\beta^{\prime}\right]^{\prime}$ and $\mathrm{W}_{\mathrm{i}}$ the vector $\left[1, \mathrm{X}_{\mathrm{i}}, \mathrm{Z}_{\mathrm{i}}\right]$. This model 
is exactly identified, so that it is possible, in principle, to determine the parameters of equation (1) and thus to calculate the average value of the VSL in the population or for groups that have different values of $\mathrm{X} .^{2}$

The implementation of this model places very considerable demands on the data typically available. In reality, the vast majority of studies settle for providing estimates of $\mathrm{V}$ among those people who accept risks. Since this is the best information that is often available, it is inevitable that we must rely on these estimates for public decisions. However, it is important to consider the limitations of this approach, just as it is important to consider the strengths.

2. How are estimates of the VSL used?

a. Traffic safety decisions

Some of the earliest use of VSL estimates, and an area that remains of great practical importance, is in the design of highways. ${ }^{3}$ Though simplified, a large number of government highway departments throughout the world engage in an analysis of two key questions virtually daily: (1) Within a given budget, what is the best way to allocate resources so as to reduce traffic fatalities? (2) Is the budget sufficient to lower fatalities to the point where the typical driver would not be willing to pay more for traffic safety.

\footnotetext{
${ }^{2}$ See Ashenfelter and Greenstone (2004) for the details.

${ }^{3}$ de Blaeij, Arianne, Raymond J.G.M. Florax, Piet Rietveld, and Erik Verhoef (2000) provide a detailed survey of estimates of the VSL derived from traffic safety data and decisions.
} 
The first question does not require a measure of the VSL, but it does make use of the key ingredients that make up that analysis. Suppose, for example, there are 3 places on three different city streets where safety improvement projects could be undertaken. And suppose that in these projects the cost of saving a life is 3.0 million, 1.0 million, and .5 million dollars, respectively. Clearly, allocating funds to the third project is wiser than allocating funds to the other projects, as you get more for your "safety buck." For half a million dollars you can save a life, while with the first project you must spend 6 times as much to do so. In short, minimizing fatalities within a given budget requires calculation of the cost per fatality saved, which is much like the calculation of $\mathrm{V}$ in the discussion above.

However, suppose that the total budget for safety projects in this city is 1.5 million dollars. Clearly, this means that only the second and third projects will be undertaken. But is this optimal? The answer to this question depends on the VSL. If the VSL is more than 3 million dollars, then clearly the third project should be undertaken also, because the typical person is willing to give up more than 3 million dollars to save a life. Thus, the VSL plays a key determinant in discussions of how big the traffic safety budget should be.

There does not seem to be a careful report of actual values used by highway departments for the VSL, but even a little brief study will reveal that this approach to highway safety is astonishingly widely used. For example, the state of 
California's department of transportation, Caltrans, uses $\$ 3,104,738$ as the VSL, and reports that the US Department of Transportation used a VSL value of $\$ 3$ million as of January 2004. ${ }^{4}$ Although estimates of the VSL in the literature range quite widely, from say $\$ 1$ million to $\$ 8$ million, it is my impression that highway departments often use estimates at the bottom end of this range and sometimes below it. If the VSL is higher than the one being used by the appropriate agency, of course, the implication is that too many fatal accidents are taking place and that the level of highway safety is sub-optimal.

b. Benefit-cost analysis of environmental regulations

The Environmental Protection Agency routinely makes use of the VSL concept in the evaluation of the costs of environmental health and safety risks. ${ }^{5}$ The basic idea is to estimate fatality risks associated with a particular environmental hazard and compel abatement to the point where the cost of an additional life saved is greater than the VSL. This is, of course, the same use of the VSL as in the analysis of traffic safety, although it is couched in different terms and often leads some observers (not economists!) to rather different conclusions about the merits of the approach.

\footnotetext{
${ }^{4}$ See http://www.dot.ca.gov/hq/tpp/offices/ote/Benefit_Cost/benefits/accidents/value estimates.html. This web site also provides a tutorial on just how to use the VSL to calculate the value of a highway safety improvement.

${ }^{5}$ See Blomquist (2004) for a thoughtful review and summary of the VSL concept that was prepared at the request of the Environmental Protection Agency.
} 
Of course, any decision by a government agency regarding safety has implications for the VSL implied by that agency's actions. Viscusi (2000) provides an example of a number of implied estimates of the VSL from various US government agency decisions. An interesting feature of these estimates is that many of them lie far above the range of $\$ 1$ to 8 million found in the literature. This implies, of course, that some environmental rules have been adopted that may be more stringent that would be optimal.

c. Medical interventions and technology

The use of the VSL in medicine is much the same as in the areas discussed above, though measures of the value of a life saved take on their own special dimensions. ${ }^{6}$ In effect, the adoption of a medical procedure is justified if its cost is low enough compared to the life years it saves.

It is not difficult to convert a VSL to the value of a life year saved (LY). If the VSL is based on the life of someone who is 40 years old, and if mortality absent the intervention is 80 , then a life saved corresponds to roughly 40 life years. In this example, if the VSL is $\$ 4$ million, then a VLY is $\$ 100$ thousand. If an intervention saves a life year and costs less than $\$ 100$ thousand, it would be considered cost effective using this standard.

\footnotetext{
${ }^{6}$ The literature and discussion of this topic is enormous, and ranges from handbooks for practitioners to discussions of ethical issues related to the use of VSL measurements.
} 
The value of a life year takes on special significance in medicine because a life may be saved, but the person whose life is saved may have far less than a normal, or even acceptable, quality of life. This leads to attempts to estimate "quality adjusted life years" (QALY). Needless to say, providing universally acceptable measures of the quality of life can generate considerable controversy.

An unusual feature of estimates of the value of QALY is the widely cited importance of a rough cut-off of $\$ 50$ thousand. This estimate comes from the national discussion of, and agreement to provide federal funds for, kidney dialysis treatments on a universal basis in 1972 with the End-Stage Renal Disease Amendment to the Medicare program, which extended coverage to patients under the age of $65 .^{7}$ Kidney dialysis costs roughly $\$ 50$ thousand per year and its provision is essential to provide a year of additional life to a patient with kidney failure. Since kidney dialysis is clearly a treatment that has been revealed preferred, it provides a lower bound on the value of a life year. It also provides, by extension, a lower bound on the VSL when it is properly adjusted. It is important to note that this method for bounding the VSL is really an application of the procedure set out formally above, though it is my impression that the medical profession discovered this method "independently" because its use is so natural.

\footnotetext{
${ }^{7}$ See Weinstein (2005) for a very readable discussion of this and related issues in the cost-effective practice of medicine.
} 
3. Problems in the measurement of a VSL

There are both conceptual issues to confront in the interpretation of estimates of a VSL as well as potentially difficult measurement issues.

\section{a. Endogeneity of risks}

Perhaps the most important issue concerning the design of a study of the VSL relates to the role of the conceptual experiment that the investigator is designing. Is there an exogenous event that will affect wealth and fatality risk to which we can observe an agent's response? If there is, then it is possible to measure the effect of the event on (a) wealth, and (b) fatality risk. The ratio of these two effects, given that the event was accepted then provides an estimate of $\mathrm{V}$ just as defined above and thus it provides a bound on the VSL.

However, such events are very difficult to isolate in practice. Consider, for example, a driver's choice of a speed. The reciprocal of the driver's speed is the hours it takes to travel a mile. Higher speeds reduce travel time, which is a form of travel cost, and reducing travel time is something that, other things the same, drivers prefer. At the same time, higher speeds will, given the condition and congestion of a road, lead to a higher risk of fatality. This suggests that we might consider the relation of speed to fatalities across roads as a measure of the causal effect of speed (or the time it saves by faster driving) on fatalities. 
It is not hard to see that the relation, across roads, between speed and fatalities is not a causal one. Instead, both fatalities and speeds are, in part, determined by a third factor, typical road condition and congestion level. When a road is safe, drivers will sensibly increase their speeds. Thus the observed relation between speed and fatalities across roads reflects two offsetting forces: one is that increased speed causes more fatalities, and the other is that higher speeds result from lower fatality risks. Whether the net effect is a positive or negative relation between speed and fatalities is unclear, but one thing is clear: absent some further assumptions, the resulting relationship does not reveal anything about the risk trade-off posed by higher speeds and thus does not provide a way to bound the VSL. $^{8}$

A common approach to measuring the VSL uses the relation between wages and fatality risks on jobs. However, it is rarely possible to compare identical jobs that face different fatality risks, and the result is similar to the endogeneity problem described above with respect to highway safety risks. The net relation between wages and fatality risks contains both the causal effect due to the higher wage demanded for higher fatality risks and the result of the effect of other factors (skill, working conditions, etc.) that effect pay and are correlated with fatality risks across

\footnotetext{
${ }^{8}$ In fact, empirically the net relation between speed and fatalities is near zero. See Ashenfelter and Greenstone (2004).
} 
job types. Whether the net effect results in a positive or negative relation between pay and fatality risk is unclear. ${ }^{9}$

b. Whose life is it, anyway?

It would be surprising if VSL did not vary across people with different preferences, across income levels, and even over the life cycle. A natural question to ask, therefore, of any VSL estimate is, just whose preferences are being measured? There is, of course, a further question. Just whose preferences do we want to measure?

In general the latter question is no doubt easier to answer than the first. When public decisions are being made we normally would like to base decisions on (and in a democratic society will base them on) the preferences of the central agent, that is, neither the agent who loves risk the most nor the agent who hates risk the most, but someone in the center of the distribution of preferences. However, many useful studies of the VSL are naturally based on risk acceptance behavior that is not in the center of the distribution, and in other cases it is unclear whose preferences are being elicited.

For example, inexpensive, effective safety devices will be adopted by virtually everyone, while expensive, ineffective safety devices will be adopted by

\footnotetext{
${ }^{9}$ See especially Black and Kniesner (2003). In more than half of their specifications, they find that for male (and female) workers fatality risks are estimated as negatively related to wage rates, implying VSL estimates that are also negative. Also see Hersch (1998) who finds a negative association between injury rates and wages for all male workers. Many other studies find a positive relation between wage rates and fatality risks, including the earliest such estimate by Thaler and Rosen (1976).
} 
few. As a result, the decision to adopt either of these two extreme types of devices provides very weak bounds on the VSL of, say, the median agent.

An extreme example of this issue can arise in studies of the labor market. Suppose that there are two jobs, one riskier than the other, and that the former comprises the proportion $\theta$ of all jobs. Suppose also that there are two types of workers, one that demands a higher premium for risky jobs than the other, and the former comprises $\lambda$ of the workers. Clearly, workers will be sorted into jobs so as to minimize employer wage costs. If $\lambda<\theta$, then the risky jobs can be filled with workers who demand the low premium, while the reverse is the case if $\lambda>\theta$. Thus, the observed premium for risk depends critically on the sorting of workers and the distribution of preferences as well as of risks. In the first case, if $\lambda<.5$ the observed premium for risk will be less than the premium that would be demanded if all workers were confronted with a risk. The reverse may, of course, also be the case.

In principle, this discussion suggests that VSL's measured from political decisions that represent the center of the distribution of preferences are the most appropriate for use in public policy decision making. However, these decisions may suffer from other problems either because they do not, in fact, represent the median preference or because the agents whose opinions are revealed are poorly informed. 


\section{c. Do they know the risks?}

A further problem is associated with the ability of agents to make informed decisions in situations where safety risks are difficult for even experts to quantify. In road safety most people have some appreciation or feeling for the risks involved, though it is far from clear that extreme risks are well understood. However, in medicine virtually everyone relies on the services of an expert or doctor to assist in assessing risks. Likewise, many environmental risks are difficult for even an expert to quantify.

In principle, the preferences revealed in the measurement of a VSL are not based on misperceptions, but are accurate. However, even if they are not, it can be argued that the trade-off between wealth and incorrect assessments of risk do reveal the VSL so long as it is know what assessments the agents relied upon in their decisions. Of course, eliciting the latter may be very difficult. ${ }^{10}$

\section{d. Agency problems}

It is often the goal to use a measure of a VSL in a public policy setting where it is useful to avoid taking the issue for decision to the public directly because doing so is excessively costly relative to the value of the decision. Decisions such as the assignment of road repair priorities are obviously more sensibly left to the highway department, for example, than to a public vote. Since

\footnotetext{
${ }^{10}$ A review of the literature on this issue is contained in Blomquist (2004)
} 
the VSL will be externally provided in the making of these decisions, it is apparent that high standards are required for its measurement.

Thus, measures of the VSL based on what may only appear to be the public's preferences must be distinguished from measures that really are based on those preferences. An especially difficult problem arises when the benefits from a risk reduction are paid for by a group different from those whose risks are reduced. Depending on the political power of the two groups, the observed decision may differ considerably from a reasonable estimate of the VSL. Viscusi (2000) provides many examples that might be interpreted from this perspective in the area of environmental regulation. The evidence suggests that in these cases the benefits of environmental regulations have been given greater weight than would be consistent with most VSL measures. This suggests that environmental groups may have played an important role in the regulatory process independent of what would be implied by the concern for fatality risks, though this is a controversial issue and there are other explanations for these findings.

4. An example of VSL measurement: speed limits

Although there have been a number of creative attempts designed to estimate the value of a statistical life, there have been few opportunities to obtain estimates based on the public's willingness to accept an exogenous and known safety risk. 
An analysis that does fall into this category is a study of highway safety risk decisions that resulted from the opportunity that the federal government gave the states in 1987 to choose a speed limit for rural interstate highways that was higher than the uniform national maximum speed limit then in existence. ${ }^{11}$ This remarkable natural experiment led 40 of the 47 states that have rural interstate highways to adopt 65 mile per hour (mph) speed limits on them, while the remaining 7 states retained $55 \mathrm{mph}$ speed limits. The basic idea is to measure the value of the time saved per incremental fatality created by the voluntary adoption of an increased speed limit. Since adopters must have valued the time saved by greater speeds more than the fatalities created, this ratio provides a convincing and credible upper bound on the value of a statistical life (VSL).

Though far from perfect, this institutional change does make it possible to address several conceptual problems noted above that have plagued attempts to estimate the value of a statistical life. First, the 1987 law provides a credible exogenous change in the safety environment. As a result it is possible to measure the effects of this exogenous change on speeds and fatality rates. The ratio of these two effects provides an estimate of $\mathrm{V}$, the trade-off the parties faced in making their decision. Second, many questions have been raised about the usefulness of studies of the value of a statistical life when the decision makers studied may be

\footnotetext{
${ }^{11}$ This example is based on Ashenfelter and Greenstone (2004).
} 
poorly informed about the relevant risks. In this case the relevant decision makers (i.e., state governments) were cognizant of the trade-offs associated with a change in speed limits. Although this does not provide conclusive evidence that the participants in the decisions were well informed, it is certainly more plausible than is often the case. Third, any VSL estimate that is based on the decisions of a third party (e.g., government policies) may not reflect the preferences of the group whose VSL is of interest. Speed limit regulations, however, provide benefits (reduced travel time) and costs (fatality risk) to precisely the same people, so that appeals to a simple model of the typical voter are far more plausible in this context. Finally, it seems perfectly reasonable to think that the voter whose preferences the state governments represented are those of someone whose preferences are toward the center of the distribution of preferences toward risk.

a. The history of speed limits in the US

The first laws imposing restrictive speed limits on motor vehicles were passed in 1901 in Connecticut. It is not surprising that speed limits have been enacted in places like Connecticut where congestion results in external effects on other drivers from any driver's speed. Indeed, the purpose of speed limits is to reduce the variability in speeds that results in unacceptable fatality risks. ${ }^{12}$ Except

\footnotetext{
${ }^{12}$ Indeed, an Indiana Department of Transportation reports states this explicitly: "Speed limits represent trade-offs between risk and travel time for a road class or specific highway section reflecting an appropriate balance between the societal goals of safety and mobility. The process of setting speed limits is not merely a technical exercise. It
} 
for a brief period during the Second World War, the setting of speed limits remained the responsibility of the state and local governments until 1974. In that year Congress enacted the Emergency Highway Energy Conservation Act in response to the perceived "energy crisis." This bill, intended as a fuel conservation measure, required, among other things, a national maximum speed limit of $55 \mathrm{mph}$. This new national speed limit was lower than the existing maximum daytime speed limit in all 50 states.

By 1976 the Federal Highway Administration began to enforce compliance with the national speed limit. Each state was required to measure compliance with the federal limit. States that did not enforce $50 \%$ compliance with the limit were penalized by a $10 \%$ reduction in federal highway funding. By 1987 dissatisfaction with the federally imposed (and enforced) national maximum speed limit led Congress to modify the law to permit states to set speed limits of $65 \mathrm{mph}$ on rural interstate highways only.

Even with the end of the concern for fuel conservation, the national maximum speed limit was retained in some form until repeal in $1995 .^{13}$ Despite opposition, especially in the wide open Western states, much of the support for

involves value judgments and trade-offs that are in the arena of the political process" See Khan, Sinha, and McCarthy, 2000, p. 144.

${ }^{13}$ By the end of 1997 only three states maintained a $55 \mathrm{mph}$ speed limit on rural interstates: 20 states had rural interstate speed limits of $65 \mathrm{mph}, 16$ were at $70 \mathrm{mph}, 10$ at $75 \mathrm{mph}$, and Montana had no daytime speed limit, returning to its policy in 1973 . 
national speed limits may have resulted from the unintended impact that this law appeared to have on motor vehicle fatalities. Figure 1 shows the history of fatalities per 100 million vehicle mile of travel (VMT) from 1966-93. It is apparent that fatalities per mile traveled had been declining during this entire period, but the decline of 15 percent (nearly 10,000 fatalities) immediately following passage of the 1974 Emergency Highway Energy Conservation Act is the largest ever recorded in a single year and was widely remarked upon at the time.

b. Did speeds and fatality rates change?

Some very simple analyses of the impact of adopting the $65 \mathrm{mph}$ speed limit on rural interstates are reported in the top panel of Table 1. The basic idea is to assume that, absent the adoption of the new speed limit, the change in speeds for non-adopters on rural interstates would equal what it would have been for the adopters had they not adopted the new speed limit. Thus the difference in these differences provides a simple estimate of a "treatment" effect due to the speed limit. It is important to determine whether actual speeds increased as, absent such an increase there, is no actual natural experiment taking place. Thus, it is important to measure the effect of the treatment on both actual speeds and on fatalities. 
Column (1) reports the raw unadjusted difference in differences (DD) estimator of the effect of the $65 \mathrm{mph}$ speed limit on fatality rates and speeds. This is calculated as the difference between the mean fatality rates and speeds between adopters and non-adopters from 1988-93 (i.e., the "post-period") minus the same difference from 1982-86 (i.e., the "pre-period"). This estimator suggests that the adoption of the $65 \mathrm{mph}$ speed limit increased fatality rates by 0.185 and speeds by 2.8 mph on rural interstates. ${ }^{14}$

The same analysis applied to the data on urban interstate and rural arterial roads is contained in the bottom two panels of Table 1. These roadtypes were not directly affected by the law change. They thus provide a test of whether they might usefully serve as an additonal control group. The entries in the table indicate that fatality rates decreased more in adopting states than non-adopting states on both categories of roads. ${ }^{15}$ When these declines are viewed in the context of the 1982-86 levels, they appear modest. If these relative declines in adopting states are due to an unobserved factor common to all roads in these states, then these roads should be used as intra-state comparisons. It is evident that controlling for this decline will increase the magnitude of the estimated effect of the $65 \mathrm{mph}$ limit on fatalities. Average speeds increased at about the same rate in adopting and nonadopting states on these roadtypes. Interestingly, the speed data contradict the 
popular "spillover" hypothesis that higher speed limits on one road cause drivers to increase their driving speed on all roads.

Column (2) reports the results of the application of the DD estimator applied to the $\ln$ transformation of the raw, state by roadtype by year data. The $\ln$ difference approach is attractive because it provides estimates of (approximately) proportionate changes in speeds and fatality rates. The estimates of the increased speed limit imply proportionate increases of 0.31 in the fatality rate and of 0.045 in speed. The estimated changes on urban interstates are quite small, at -0.063 and 0.009, while they are even smaller at 0.005 and 0.008 on rural arterials. These results suggest that it is worth considering the results of using both urban interstate and rural arterial roads as additional control group for the analysis of rural interstate road.

\section{c. Estimates of the VSL}

Estimates of an upper bound on the VSL are contained in Tables 2 and 3. There two separate analyses because, in this case, the results depend on the precise specification of the way the trade-off between travel time saved and fatality risks is measured. In Table 2 the analysis is done using logarithmic (proportionate) changes, while in the Table 3 the analysis is done in natural units. In each table there are 10 different estimates of the VSL depending on which groups are used for 
the comparison, adopters vs. non-adopters on rural interstates being used as a part of the comparison throughout. The other estimates differ to the extent that urban interstate and rural arterial roads are used as part of the control group for comparison. They also differ in the extent to which detailed controls are used to adjust for state, year, and roadtype changes that might confound estimates of the effect of the speed limit on speeds and fatalities.

For each specification in each table there are three numbers. The first is the estimate of the trade-off between hours saved and fatality risk. ${ }^{16}$ The second is the estimate of the standard error of the parameter estimated, while the third is transformed by the value of time to provide a measure of the VSL.

It is apparent from the tables that the estimates of the VSL are fairly sensitive to the specification assumed for the analysis, though the range of estimates may provide a workable basis for broad conclusions. Using the rural interstate roads as comparators only, the estimates of the VSL are \$1.6 million for the analysis in levels and $\$ 6.0$ million for the analysis in logarithms. In general, this difference is typical of those in the tables and these two numbers provide pretty representative estimates from each table, though smaller and larger VSL estimates can be found in them. The primary advantage of these estimates is the extent to which they can withstand scrutiny based on the conceptual issues

\footnotetext{
${ }^{16}$ These are estimates of a regression of the hours it takes to travel a mile on fatalities, with the state-year interaction associated with the adoption of the 65 mile per hour speed limit used as an instrumental variable for fatalities.
} 
associated with measuring the VSL. Their biggest disadvantage is that they are not unambiguously independent of the specification used to produce them.

\section{Prospects}

It has been just thirty years during which economists have defined, quantified, and critiqued the operational definition of safety risks summarized as the Value of a Statistical Life. Looking back, this is quite a remarkable accomplishment. The basic theory is both widely understood and taught, but also used in public decisions in many areas. Measurements of the VSL are essential for decisions based on these ideas, and apparently the precision of the estimates we have is considered better than the use of no measurements at all. Of course, there is room for much improvement, and no doubt there will be a great deal of it. 


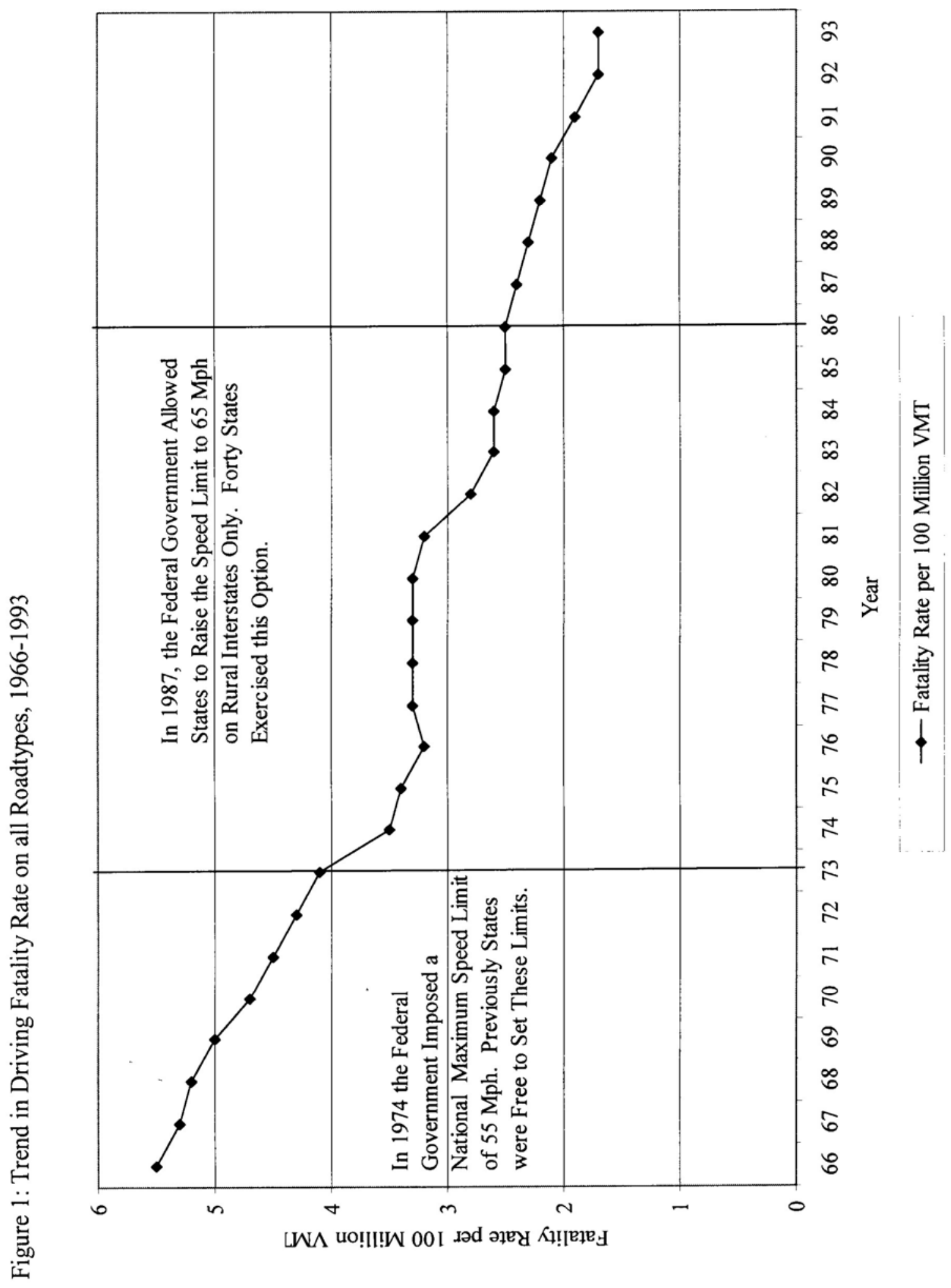


Table 1: Difference in Differences (DD) Estimates of 65 Mph Speed Limit on Fatality Rates and Speeds

$\begin{array}{cc}\text { DD of Levels } & \frac{\text { DD of Natural }}{\underline{\text { Logarithms }}}\end{array}$

(1) (2)

Rural Interstates (Affected Roadtype)

Fatality Rate $\quad 0.185$

Speed 2.8

0.311

Urban Interstates (Unaffected Roadtype)

Fatality Rate $\quad-0.052$

0.045

Speed

$-0.5$

$-0.063$

$-0.009$

Rural Arterials (Unaffected Roadtype)

Fatality Rate $\quad-0.123$

0.005

Speed

0.5

0.008

Notes: The entries in this table represent two difference in differences (DD) estimates of the effects of the $65 \mathrm{mph}$ speed limit on fatality rates and speeds. The column (1) entries are the raw DD estimates. The column (2) entries are calculated with the mean of $\ln$ (fatality rate) and $\ln$ (speed) for adopters and non-adopters in the pre and post periods. The entries are equal to the post - pre difference of weighted means among adopters minus the post - pre difference of weighted means among nonadopters, where the weight is vehicle miles of travel. The pre-period is defined as $1982-86$ and the post-period is $1988-93$. 
Table 2: Estimates of the Monetary Value of the Time Saved per Marginal Fatality

\begin{tabular}{|c|c|c|c|}
\hline Sample & (1) & (2) & (3) \\
\hline \multicolumn{4}{|c|}{ Functional Form I: Ln Transformation } \\
\hline $\begin{array}{l}\text { Rural Interstates } \\
\text { Only }\end{array}$ & -------- & $\begin{array}{c}-0.113^{* *} \\
(.037) \\
{[\$ 1.64 \text { million] }}\end{array}$ & --------- \\
\hline $\begin{array}{l}\text { Rural Interstates \& } \\
\text { Urban Interstates }\end{array}$ & $\begin{array}{c}-0.095^{*} \\
(.040) \\
{[\$ 1.38 \text { million] }}\end{array}$ & $\begin{array}{c}-0.076^{*} \\
(.034) \\
{[\$ 1.11 \text { million }]}\end{array}$ & $\begin{array}{c}-0.076^{* *} \\
(.031) \\
{[\$ 1.11 \text { million }]}\end{array}$ \\
\hline $\begin{array}{l}\text { Rural Interstates \& } \\
\text { Rural Arterials }\end{array}$ & $\begin{array}{c}-0.166^{* *} \\
(.057) \\
{[\$ 2.42 \text { million] }}\end{array}$ & $\begin{array}{c}-0.146^{*} \\
(.066) \\
{[\$ 2.12 \text { million] }}\end{array}$ & $\begin{array}{c}-0.122 * \\
(.051) \\
{[\$ 1.78 \text { million] }}\end{array}$ \\
\hline All Three & $\begin{array}{c}-0.128^{* *} \\
(.042) \\
{[\$ 1.86 \text { million }]}\end{array}$ & $\begin{array}{c}-0.103 * * \\
(.041) \\
{[\$ 1.50 \text { million }]}\end{array}$ & $\begin{array}{c}-0.099 * * \\
(.034) \\
{[\$ 1.44 \text { million }]}\end{array}$ \\
\hline Year Indicators & Yes & No & No \\
\hline Year-Roadtype Indicators & No & Yes & Yes \\
\hline State-Roadtype Indicators & Yes & Yes & Yes \\
\hline State-Year Indicators & No & No & Yes \\
\hline
\end{tabular}

Notes. For details see Ashenfelter and Greenstone (2004). The entries report the results from regressions of $\ln$ (Hours of Travel) on $\ln$ (Fatalities), where an indicator for whether the $65 \mathrm{mph}$ speed limit was in force is an instrumental variable. The details of the controls on roadtype and year and state effects are in the stub of the table. Ln (VMT) is a control and its effect is allowed to vary by roadtype. The entries are the parameter estimates and heteroskedastic consistent standard errors (in parentheses) on ln (Fatalities) and the implied monetary value of the time saved per marginal fatality, $\mathrm{V}$, [in square brackets]. $*$ indicates significance at $5 \%$ level, $* *$ indicates significance at $1 \%$ level. 
Table 3: Estimates of the Monetary Value of the Time Saved per Marginal Fatality

\begin{tabular}{|c|c|c|c|}
\hline Sample & (1) & (2) & (3) \\
\hline \multicolumn{4}{|c|}{ Functional Form II: Untransformed } \\
\hline $\begin{array}{l}\text { Rural Interstates } \\
\text { Only }\end{array}$ & -------- & $\begin{array}{c}17.03^{*} \\
(7.67) \\
{[\$ 5.92 \text { million] }}\end{array}$ & --------- \\
\hline $\begin{array}{l}\text { Rural Interstates \& } \\
\text { Urban Interstates }\end{array}$ & $\begin{array}{c}25.64 * * \\
(9.42) \\
{[\$ 8.91 \text { million] }}\end{array}$ & $\begin{array}{c}16.39^{*} \\
(7.46) \\
{[\$ 5.69 \text { million] }}\end{array}$ & $\begin{array}{c}8.65^{*} \\
(3.84) \\
{[\$ 3.00 \text { million }]}\end{array}$ \\
\hline $\begin{array}{l}\text { Rural Interstates \& } \\
\text { Rural Arterials }\end{array}$ & $\begin{array}{c}4.01 * * \\
(0.51) \\
{[\$ 1.39 \text { million] }}\end{array}$ & $\begin{array}{c}8.25 \\
(4.32) \\
{[\$ 2.87 \text { million] }}\end{array}$ & $\begin{array}{c}7.88^{*} \\
(3.79) \\
{[\$ 2.74 \text { million] }}\end{array}$ \\
\hline All Three & $\begin{array}{c}6.97 * * \\
(1.16) \\
{[\$ 2.42 \text { million }]}\end{array}$ & $\begin{array}{c}11.98^{*} \\
(5.06) \\
{[\$ 4.16 \text { million }]}\end{array}$ & $\begin{array}{c}8.80 * * \\
(3.57) \\
{[\$ 3.06 \text { million] }}\end{array}$ \\
\hline Year Indicators & Yes & No & No \\
\hline Year-Roadtype Indicators & No & Yes & Yes \\
\hline State-Roadtype Indicators & Yes & Yes & Yes \\
\hline State-Year Indicators & No & No & Yes \\
\hline
\end{tabular}

Notes: The entries report the results from regressions of speed on fatality rates, where an indicator for whether the $65 \mathrm{mph}$ speed limit was in force is an instrumental variable. The equation is weighted by the square root of VMT. The details of the controls on roadtype and year and state effects are in the stub of the table. The entries are the parameter estimates and heteroskedastic consistent standard errors (in parentheses) on the fatality rate and the implied monetary value of the time saved per marginal fatality, $\mathrm{V}$, [in square brackets]. * indicates significance at $5 \%$ level, $* *$ indicates significance at $1 \%$ level 


\section{References}

Ashenfelter, Orley and Michael Greenstone. "Using Mandated Speed Limits to Measure the Value of a Statistical Life," Journal of Political Economy, 112 (2004): S226S267.

Black, Dan A. and Thomas J. Kniesner. "On the Measurement of Job Risk in Hedonic Wage Models." Mimeograph, University of Syracuse, March 2003.

Blomquist, Glenn C. "Self Protection and Averting Behavior, Values of Statistical Lives, and Benefit Cost Analysis of Environmental Policy." Review of Economics of the Household 2 (2994): 89-110.

de Blaeij, Arianne, Raymond J.G.M. Florax, Piet Rietveld, and Erik Verhoef. "The Value of a Statistical Life in Road Safety: A Meta-Analysis." Tinbergen Institute Discussion Paper No. 2000-089/3, 2000.

Heckman, James J. "Sample Selection Bias as a Specification Error." Econometrica, 47 (1979): 153-62.

Hersch, Joni. "Compensating Differentials for Gender-Specific Injury Risks." American Economic Review 88(1998): 598-607.

Khan, Nisar, Kumares C. Sinha, and Patrick S. McCarthy. "An Analysis of Speed Limit Policies for Indiana." FHWA/IN/JTRP-99/14, Joint Transportation Research Project, Purdue University, West Lafayette, IN, 2000.

American Economic Review 88(1998): 598-607.

Thaler, Richard, and Rosen, Sherwin. "The Value of Saving a Life: Evidence from the Labor Market," in Household Production and Consumption. Nestor E. Terleckyj, ed., Cambridge, MA: NBER, 1976: 265 - 298.

Viscusi, W. Kip. "The Value of Life in Legal Contexts: Survey and Critique." American Law and Economics Review, 2 (2000): 195-222.

Weinstein, Milton. "Spending Health Care Dollars Wisely: Can Cost-Effectiveness Analysis Help?” Policy Brief No. 30/2005, Syracuse University, 2005. 